\title{
Cannabis and Pain Treatment-A Review of the Clinical Utility and a Practical Approach in Light of Uncertainty
}

\author{
Simon Vulfsons, M.D. ${ }^{1,2 *}$, Amir Minerbi, M.D., Ph.D. ${ }^{1,3}$, and Tali Sahar, M.D. ${ }^{4,5,6}$ \\ ${ }^{\prime}$ Institute for Pain Medicine, Rambam Health Care Campus, Haifa, Israel; ${ }^{2}$ Rappaport School of Medicine, \\ Technion Institute of Technology, Haifa, Israel; ' Alan Edwards Centre for Research on Pain, Montreal, \\ Quebec, Canada; ${ }^{~}$ Pain Relief Unit, Department of Anesthesia, Hadassah Medical Center, Jerusalem, \\ Israel; ${ }^{5}$ Supportive Care \& Pain Relief Clinic, Clalit Health Services, Jerusalem District, Israel; and \\ ${ }^{6}$ Department of Family Medicine, Hebrew University of Jerusalem, Jerusalem, Israel
}

\begin{abstract}
Over the past decade the phenomenon of cannabis as a legitimate form of treatment for pain has overwhelmed the medical community, especially in the field of pain. From a status of a schedule 1 substance having no currently accepted medical use and being considered to have high potential for abuse, its use has mushroomed to over 50,00o legal medical users per year in Israel alone. There appear to be many reasons behind this phenomenon-medical, sociological, and economical. Thus, what is cannabis? An abusive substance or a medication? Should it be incorporated into current biomedical practice, and how should it be administered? Finally, what is the evidence for the beneficial and detrimental effects of cannabis? This article reviews and discusses the current literature regarding the beneficial and the detrimental effects of
\end{abstract}

\begin{abstract}
Abbreviations: CBD, cannabidiol; DDI, drug-drug interactions; MS, multiple sclerosis; NSAID, non-steroidal antiinflammatory drugs; NNH, number needed to harm; NNT, number needed to treat; RCT, randomized controlled trials; THC, tetrahydrocannabinol.

Citation: Vulfsons S, Minerbi A, Sahar T. Cannabis and Pain Treatment-A Review of the Clinical Utility and a Practical Approach in Light of Uncertainty. Rambam Maimonides Med J 2020;11 (1):eooo2. Review. doi:10.5041/RMMJ.10385

Copyright: (C) 2020 Vulfsons et al. This is an open-access article. All its content, except where otherwise noted, is distributed under the terms of the Creative Commons Attribution License (http://creativecommons.org/licenses/by/3.0), which permits unrestricted use, distribution, and reproduction in any medium, provided the original work is properly cited.
\end{abstract}

Acknowledgment: We thank Ms Leeat Benny (head of the Medical Cannabis Association, a non-profit organization based in Israel) for her able assistance in formulating the table.

Conflict of interest: No potential conflict of interest relevant to this article was reported.

* To whom correspondence should be addressed. E-mail: s_vulfsons@rambam.health.gov.il 
medical cannabis in the treatment of pain. We further discuss the problems and challenges facing the medical community in this domain and offer a practical approach to deal with these challenges.

KEY WORDS: Beneficial effects, cannabis, cannabis for therapeutic purposes, medical cannabis, review, side effects

\section{INTRODUCTION}

Over the past decade the phenomenon of cannabis as a legitimate form of treatment for pain has overwhelmed the medical community, especially in the field of pain. From a status of a schedule 1 substance, ${ }^{1}$ having no currently accepted medical use and being considered to have high potential for abuse, its use has mushroomed to over 50,00o legal medical users per year in Israel alone (Ministry of Health: personal communication). There appear to be many reasons behind this phenomenon. Opiate medications, used and abused over the last two decades, have brought about a crisis in treatment-the opioid overdose crisis. ${ }^{2-4}$ In a nutshell, prescription opiates have brought about a huge rise in all-cause mortality in the United States, leading to over 130 deaths per day, with an estimated cost of 78.5 billion dollars in healthcare, lost productivity, addiction treatment, and criminal justice involvement. ${ }^{5,6}$ In October 2017 the opioid crisis was declared by presidential decree to be a public health emergency in the United States.7 This crisis in prescription medications for the treatment of pain has arisen on the tail of a previous crisis: that of the adverse effects of non-steroidal anti-inflammatory drugs (NSAIDs). ${ }^{8}$ The NSAIDs crisis became most apparent after the article by Wolfe et al. in 1999. ${ }^{9}$ Thus, from a medical point of view, two mainstays of the pharmacological treatment of chronic pain, NSAIDs and opiates, are now deemed inappropriate and dangerous, leaving a vacuum which is being filled by cannabis.

Other reasons behind the role that cannabis is taking in the treatment of pain include massive campaigns for the decriminalization and legalization of cannabis, as well as the so-called "medicalization" of cannabis. ${ }^{10,11}$ Bostwick, in a seminal paper in 2012, described the blurred boundaries between cannabis as a medical agent and cannabis as a recreational one.12 In fact the boundaries between recreational and "medical" cannabis use is constantly negotiated between stakeholders as part of the regulatory boundary-work, depending on each stakeholder's particular interests. ${ }^{13}$ The medicalization of cannabis is contested by stakeholders, and in Israel this is an ongoing process. ${ }^{14}$ The Israeli government authority for cannabis has opted for a biomedical approach, viewing cannabis as a biological substance that can be incorporated into medical practice, although marked uncertainty exists concerning optimal strains, concentrations, doses, and modes of delivery. In contrast to the Israeli cannabis authority, physicians' attitudes and views, in Israel, are far less accepting towards this substance. ${ }^{15}$ An earlier study suggested that Israeli physicians exhibited partial acceptance of medical cannabis as a therapeutic agent, ${ }^{16}$ while a later in-depth study has shown a conflicted view of physicians' acceptance of medical cannabis. ${ }^{17}$ Public opinion can be swayed by media coverage, as evidenced in a study published in 2015 in which it was found that $69 \%$ of news articles in the three major daily newspapers in Israel framed cannabis as a medicine. ${ }^{18}$

Thus, what is cannabis? An abusive substance or a medication? Should it be incorporated into current biomedical practice, and how should it be administered? Finally, what is the evidence for the beneficial and detrimental effects of cannabis?

In this article we will discuss the beneficial effects, the detrimental effects, and the problems and challenges facing the medical community concerning cannabis in the treatment of pain.

\section{CANNABIS: BENEFICIAL EFFECTS IN PAIN TREATMENT}

The classification of pain dictates that we approach the question of beneficial effects by subgrouping pain into various types. Acute pain, often considered to be a symptom of tissue damage and nociceptive activation, is very different from chronic pain, often considered a disease in its own right. ${ }^{19}$ Thus, we will attempt to describe the evidence of different subgroups of pain. 


\section{Acute Pain}

The response of patients, suffering from acute pain, to pharmaceutical and herbal cannabinoids has been explored both in the clinical setting and in laboratory conditions on healthy volunteers.

Pain reduction was examined in a trial of 40 women undergoing abdominal hysterectomy and receiving a single dose of either $5 \mathrm{mg}$ of $\delta$-9tetrahydrocannabinol in capsule form or placebo. No analgesic effect was observed in either group. ${ }^{20}$ In contrast, escalating doses of 5,10 , and $15 \mathrm{mg}$ cannabis extract were used for post-surgical patients after patient-controlled analgesia cessation with dose response for decreasing pain intensity at rest, increasing sedation, and more adverse events. ${ }^{21}$ In an experimental trial of 18 healthy volunteers, oral cannabis extract or placebo were administered after induction of pain either in a sunburn model or an intradermal capsaicin injection model. No pain reduction was found in either the active or placebo medications. ${ }^{22}$ Other synthetic cannabinoids have also been tested for pain reduction on the model of postoperative pain. Forty-one patients underwent a double-blinded, randomized, placebo-controlled, parallel group trial post-surgery with nabilone, an oral synthetic tetrahydrocannabinol (THC) analogue with either $1 \mathrm{mg}$ or $2 \mathrm{mg}$ nabilone, ketoprofen 50 $\mathrm{mg}$, or placebo. There were four groups altogether. Outcome measures were pain scores, morphine consumption, and emesis. There was no difference in pain scores between the groups. In fact, the higher dose of nabilone $2 \mathrm{mg}$ was associated with increased pain at rest. ${ }^{2} 3$

In summary, it appears that cannabis is not an effective analgesic agent in the acute pain setting.

\section{Chronic Pain}

\section{Neuropathic and central pain}

In a meta-analysis of cannabis-based treatments for neuropathic and multiple sclerosis (MS)-related pain, 7 randomized, double-blinded, placebo-controlled trials were included ( $n=298$ patients). ${ }^{24}$ The overall quality of the studies was very good. In general, the overall reductions in pain were in excess of 1.5 points on an 11-point scale and were all statistically significant. The difference in effect size in comparison to placebo was 0.8 . This difference, however, is considered barely clinically significant. 25,26

In a systematic review of cannabinoids for the treatment of non-cancer pain, 18 trials published between the years of 2003 and 2010 involving 766 participants were included. ${ }^{27}$ The quality of the trials was good, and in 15 of the 18 trials there was a significant analgesic effect for the cannabinoid being tested. Four of the trials examined the effect of smoked cannabis on neuropathic pain, all reporting positive effects with minimal or no serious adverse effects. The mean treatment duration was only 8.5 days. Seven trials examined the effects of oromucosal extracts of cannabis-based medicine. Five trials examined the effect on participants with neuropathic pain, and four of these reported positive analgesic effects that were generally modest. Nabilone $2 \mathrm{mg}$ has been found to be as effective as dihydrocodeine $240 \mathrm{mg}$ for patients with neuropathic pain. ${ }^{28}$ Dronabinol $10 \mathrm{mg}$ has been found to be modestly effective for central pain in MS. ${ }^{29}$

In an update of their previous systematic review of randomized controlled trials (RCTs) for cannabinoids for the treatment of chronic non-cancer pain, Lynch and Ware added 11 trials that met the inclusion criteria. ${ }^{\circ}$ They included randomized controlled trials published from 2010 to 2014 involving 1,185 subjects. Of these studies, seven demonstrated significant analgesic effects. Taken with the original systematic review by the same authors, 22 of 29 RCTs have demonstrated that cannabinoids demonstrate a modest analgesic effect and are safe in the management of chronic pain. ${ }^{27}$ It should be noted that of these 29 studies the following modes of delivery were explored: smoked cannabis (6 trials), oromucosal and oral cannabis extract (11 trials), nabilone ( 8 trials), dronabilone (2 trials), THC-11oic acid analogue ( 2 trials), and fatty acid amide hydrolase inhibitor (FAAH) inhibitor (1 trial). In summary, the 6 smoked cannabis trials all showed a positive analgesic response, 10 of the 11 oromucosal and oral extract trials showed a positive analgesic response, 6 of the 8 trials examining the analgesic effects of nabilone were positive, both dronabinol trials had positive analgesic effect, and neither the THC-11-oic acid analogue nor the FAAH inhibitor trials showed lasting positive analgesic effects. All articles declared modest analgesic effects at best.

\section{Musculoskeletal pain}

Chronic musculoskeletal pain affects a large percentage of the population, including arthritis, back pain, and post-trauma/surgical pain. ${ }^{31-33}$ A recent critical review of the literature was published addressing this chronic pain population. $34 \mathrm{~A}$ total of 118 trials were included in the study, of which 33 were considered as covering "core orthopedic topics" (arthritis, back pain, trauma-related and postopera- 
tive pain). A large proportion of studies were observational, and there were very few level I randomized control studies in the core orthopedic topics. In summary the authors concluded that there is little high-quality evidence for effective analgesia in core orthopedic musculoskeletal pain, but the "best available" evidence suggests cannabis may be effective for managing arthritis pain, back pain, and traumarelated pain, although the quality of the evidence is poor.

\section{Fibromyalgia}

A Cochrane systematic review published in 2016 on the use of cannabinoids to treat fibromyalgia found only two studies of at least four weeks' duration that compared cannabinoids to either placebo or amitriptyline. 35 The cannabinoid studied was nabilone 1 mg per day at bedtime. The authors found no convincing, unbiased, high-quality evidence suggesting that nabilone is of value in treating people with fibromyalgia. Furthermore, the tolerability of nabilone was low in people with fibromyalgia. ${ }^{36,37}$

Worthy of mention is a study published in 2019 where four varieties of pharmaceutical grade cannabis were administered by single shot vapor to patients suffering from fibromyalgia. The rigorous design of the study explored the effect of: (1) high THC content (Bedrocan: THC $22.4 \mathrm{mg}$, cannabidiol [CBD] 1 mg); (2) balanced THC/CBD content (Bediol: THC $13.4 \mathrm{mg}$, CBD $17.8 \mathrm{mg}$ ); (3) high CBD content (Bedrolite: CBD $18.4 \mathrm{mg}$, THC $1 \mathrm{mg}$ ); and (4) placebo. ${ }^{8}$ None of the treatments had an effect greater than placebo on spontaneous or electrical evoked pain responses, although more subjects receiving Bediol (balanced THC/CBD content) displayed a 30\% decrease in pain scores compared to placebo (90\% versus $55 \%$ of patients, $P=0.01$ ), with spontaneous pain scores correlating with the magnitude of drug high. It is impossible to extrapolate the long-term effect of vaporized cannabis on fibromyalgia patients.

\section{Symptoms accompanying chronic pain}

Chronic pain patients carry a high prevalence of accompanying symptoms such as depression, sleep disturbances, fatigue, decrease in daily function, cognitive dysfunction, and more. $39 \mathrm{~A}$ few reports in the literature have described the effect of cannabinoids on quality of life symptoms in chronic pain patients. In a prospective open label study, 274 patients were followed for six months. Only 176 patients completed the study. Mild improvements were found in pain symptom, severity, and interference scores. $4^{40}$ In a cross-sectional survey study, 56 fibromyalgia patients completed the study, of whom 28 (50\%) were cannabis users, mainly smokers. The cannabis had been used for up to three years. In the quality of life scales there was a mild increase in the mental health component summary score of the SF-36 questionnaire, but no difference was found between cannabis users and non-users for the fibromyalgia impact questionnaire or the Pittsburg sleep quality index. ${ }^{41}$

Thus, it is safe to say that quality of life indices improve only slightly, if at all, for fibromyalgia patients using cannabis.

In summary of the beneficial effects of cannabis and cannabis-related substances in the treatment of pain, it appears that cannabis is not effective in the treatment of acute pain, has mild beneficial effects for neuropathic pain, and may be effective in core orthopedic musculoskeletal pain. In general, the level of studies of cannabinoids for neuropathic pain were good, while the studies for musculoskeletal pain were poor.

\section{CANNABIS: ADVERSE EFFECTS, DRUG- DRUG INTERACTIONS, AND SPECIAL CONSIDERATIONS}

Since the cannabis plant (Cannabis sativa L.) contains more than 100 phytocannabinoids and since cannabinoid receptors are found throughout the human body, any discussion about medical cannabis is bound to be a simplified description of a highly complex system that involves multivariate interactions.

It has been suggested that the complex biosystem of cannabis could explain both the high number needed to treat (NNT; since it takes time for the patients to find their ideal treatment) and the low number needed to harm (NNH; since $20 \%-80 \%$ of the patients experience side effects). ${ }^{25}$ Fortunately, most side effects are transient and generally well tolerated, ${ }^{38,42}$ yet some adverse effects may be detrimental, especially in vulnerable populations (Table 1)..$^{8}$

Several systematic reviews of RCTs and of safety studies have examined the adverse events following short-term treatment with medical cannabis. ${ }^{30,40-42}$ Unfortunately, when systematically reviewed, many of these trials are judged as low-quality studies with a high risk of bias.35,44 Disappointingly, many of the reviewed RCTs lacked quantifiable adverse event data or did not report any data regarding adverse events. 43 Authors agree that the rate of adverse events is likely underreported.42,43 This may change 
Table 1. A Literature-based Summary of Medical Cannabis-related Adverse Events According to the Involved Biosystems. ${ }^{27,30,35-38,40-58}$

\begin{tabular}{|c|c|c|c|}
\hline Biosystem & & Adverse Events & \\
\hline $\begin{array}{l}\text { CNS-Related: } \\
\text { Neurological and } \\
\text { Cognitive } \\
\text { (References: } 27,30,35- \\
38,40-51,56,58 \text { ) }\end{array}$ & $\begin{array}{l}\text { - Drowsiness } \\
\text { - Dizziness } \\
\text { - Heaviness } \\
\text { - Vertigo } \\
\text { - Confusion } \\
\text { - Fatigue / lethargy / } \\
\text { - somnolence } \\
\text { - Impaired attention / lack of } \\
\text { concentration / mental } \\
\text { clouding }\end{array}$ & $\begin{array}{l}\text { - Disorientation } \\
\text { - Impaired memory } \\
\text { - Impaired } \\
\text { psychomotor skills / } \\
\text { incoordination / } \\
\text { ataxia / higher rate } \\
\text { of MVAs } \\
\text { - Numbness } \\
\text { - Slurred speech }\end{array}$ & $\begin{array}{l}\text { - } \text { Blurred vision / diplopia } \\
\text { - Impaired hearing / } \\
\text { tinnitus } \\
\text { - Headaches / migraine } \\
\text { - Hyperalgesia / } \\
\text { increased pain }\end{array}$ \\
\hline $\begin{array}{l}\text { CNS-Related: } \\
\text { Psychological } \\
\text { (References: } 27,30,35- \\
\text { 38,40-49,52,54,58) }\end{array}$ & $\begin{array}{l}\text { - Restlessness / anxiety / } \\
\text { nervousness } \\
\text { - Depressed mood / depression / } \\
\text { dysphoria } \\
\text { - Euphoria / feeling high } \\
\text { - Feeling abnormal }\end{array}$ & $\begin{array}{l}\text { - Confusion } \\
\text { - Disinterest } \\
\text { - Dissociation } \\
\text { - Hallucinations } \\
\text { - Hyperactivity }\end{array}$ & $\begin{array}{l}\text { - Nightmares / weird } \\
\text { dreams } \\
\text { - Paranoia } \\
\text { - Racing thoughts } \\
\text { - Psychosis }\end{array}$ \\
\hline $\begin{array}{l}\text { Cardiovascular and } \\
\text { ANS } \\
\text { (References: } 27,30,35- \\
38,40-46,53,55,58 \text { ) }\end{array}$ & $\begin{array}{l}\text { - Myocardial infarction } \\
\text { - CVA } \\
\text { - Abnormal heart rate } \\
\text { - Cardiac disorders } \\
\text { - Hypertension }\end{array}$ & $\begin{array}{l}\text { - Hypotension / } \\
\text { orthostatic / } \\
\text { hypotension } \\
\text { - Palpitations } \\
\text { - Tachycardia }\end{array}$ & $\begin{array}{l}\text { - Sweating / diaphoresis } \\
\text { / hot flushes / facial } \\
\text { flushes } \\
\text { - Red eyes / dry eyes / } \\
\text { rash / dry skin }\end{array}$ \\
\hline $\begin{array}{l}\text { GI and Metabolism } \\
\text { (References: } 27,30,35- \\
38,40-46,53,58)\end{array}$ & $\begin{array}{l}\text { - Nausea / vomiting / } \\
\text { hyperemesis } \\
\text { - Loss of appetite / increased } \\
\text { appetite / thirst } \\
\text { - Abdominal discomfort / pain } \\
\text { - Anorexia }\end{array}$ & $\begin{array}{l}\text { - Bad taste } \\
\text { - Constipation } \\
\text { - Diarrhea } \\
\text { - Dry mouth } \\
\text { - Dyspepsia / epigastric } \\
\text { distress }\end{array}$ & $\begin{array}{l}\text { - Glossodynia / } \\
\text { hypoesthesia } \\
\text { - Oral / mucosal } \\
\text { ulceration / irritation / } \\
\text { sore mouth }\end{array}$ \\
\hline $\begin{array}{l}\text { Other Mechanisms } \\
\text { (References: } \\
\text { 27,30,38,40- } \\
46,48,54,56-58 \text { ) }\end{array}$ & $\begin{array}{l}\text { - Infections and infestations: } \\
\text { aspergillosis / pharyngitis / } \\
\text { URTI / dyspnea } \\
\text { - Respiratory: cough } \\
\text { - Hoarseness }\end{array}$ & $\begin{array}{l}\text { - Tobacco-related } \\
\text { (concomitant use } \\
\text { with tobacco): } \\
\text { chronic lung disease } \\
\text { - Endocrine: decreased } \\
\text { LH / FSH / GH / } \\
\text { prolactin }\end{array}$ & $\begin{array}{l}\text { - Immunological: } \\
\text { aggravated MS } \\
\text { symptoms / MS relapse } \\
\text { - Drug-drug interactions: } \\
\text { elevated liver enzymes } \\
\text { - Hepatobiliary disorders }\end{array}$ \\
\hline
\end{tabular}

ANS, autonomic nervous system; CNS, central nervous system; CVA, cerebrovascular accident: FSH, folliclestimulating hormone; $\mathrm{GH}$, growth hormone; GI, gastrointestinal; $\mathrm{LH}$, luteinizing hormone; MS, multiple sclerosis; MVA, motor vehicle accident; URTI, upper respiratory tract infection.

in the future, since it appears that newer studies are of better quality. $3^{\circ}$ Furthermore, the cannabis and cannabinoid preparations studied are diverse and have substantial pharmacokinetic differences, therefore care should be taken when citing or drawing conclusions from these studies. ${ }^{30}$
The consequences of long-term treatment with medical cannabis have not been fully examined. ${ }^{46}$ Most of the RCTs with medical cannabis were of very short duration, generally several days. 47 Longerduration studies rarely lasted more than four weeks. This may lead to confusion for clinicians as well as 
patients and policymakers 47 ; medical cannabis is currently prescribed for much longer periods, from several months to many years and even for lifetime.

Therefore, the literature regarding long-term adverse effects is based on experience with long-term recreational use of cannabis, rather than on RCTs of medical cannabis. ${ }^{8}$ Such studies suggest that, in the long run, cannabis can cause dependency, as well as cognitive changes, 49 anatomical brain damage,,$^{0,51}$ and psychosis. ${ }^{2}$

Side effects of short-term treatment are very common, but in the most part these are not serious. 43 They may differ from person to person, and even the same person may experience different side effects at different times. Many factors influence the probability and the severity of adverse events, such as: type of cannabinoid preparation 47 ; the mode of administration 45 ; the patient's attitude and expectations 53 as well as age 54,55; and drug-drug interactions. .66,58 $^{6}$

In contrast to prescription medications, cannabis and cannabinoids are not a single agent and thus have multiple and diverse side effects. Moreover, certain side effects can have a conflicting effect. For example, cannabis can cause either hypotension or hypertension, weight gain or weight loss, euphoria or anxiety. This has been attributed by some researchers to the non-linear concentration-effect curve of cannabis. For some effects of endocannabinoids and cannabinoids the concentration-effects curve seems to have an inverted U shape: when a maximum effect is reached, further increases of concentration decrease the effect or even cause an opposite effect due to desensitization and downregulation of receptors. 58

Therefore, we present these side effects according to the biological mechanisms that drive them, hoping that it will serve as a simple scheme for patients and clinicians.

Practically, if a patient experiences symptoms in any of these systems while treated with medical cannabis, the clinician may suggest reducing the doses, changing concentrations or modes of administration, and, in severe cases, considering discontinuation.

A safe way to reduce or avoid side effects is gradual titration of low doses of cannabinoids ("start low and go slow").58-60

There is evidence that higher doses and higher initial cannabinoid doses, as well as fast titration, can increase adverse events, with no symptomatic benefits (sometimes related to as an upside down "U"-shaped response curve). 58,59

\section{Drug-Drug Interactions}

Both THC and CBD are metabolized by the liver cytochrome P450 (CYP-450) system. Cannabinoids may act as substrates, inhibitors, or inducers of various CYP-450 isoforms. Moreover, medical cannabis is often prescribed for people with complicated medical conditions ${ }^{61}$ and is often co-administered with various medications. Accordingly, potential drug-drug interactions (DDI) of cannabinoids with other drugs or herbs are multiple and often overlooked, by both prescribers and patients.

Several reviews 56,62 have examined this topic and found that DDIs are very common not only with formulations containing THC, but even with pure $\mathrm{CBD},{ }^{6}$ which has mistakenly gained reputation as an inert compound. Drug-drug interactions are often dose-dependent and possibly less predictable in edible CBD products or in elderly patients. 55

A professional committee of the Pharmaceutical Society of Israel 57 has summarized the data from several pharmaceutical databases and created a table of the main DDI with dozens of medications and herbs according to the underlying mechanisms of interaction. Brown and Winterstein ${ }^{5}$ also offer such tables in their review. We suggest that healthcare providers carefully follow patients that are concomitantly taking other medications or herbs, surveying for possible DDIs that are published in pharmaceutical data bases. Special attention should be given to medications with neurological, respiratory, or psychiatric effects.

\section{Pregnancy}

There is growing concern regarding the use of products that contain THC and/or CBD during pregnancy and breastfeeding. Recently the United States Food and Drug Administration (FDA) strongly advised against the use of CBD, THC, or marijuana, in any form, during pregnancy and while breastfeeding. ${ }^{63}$ The FDA's recommendation is based on that of the US Surgeon General's Advisory. ${ }^{64}$ Cannabis and cannabinoids in pregnancy are associated with adverse outcomes, including lower birth weight. 65 Moreover, exogenous cannabinoids may interfere with the delicate balance of the endocannabinoid system regulation of the female reproductive system. ${ }^{66}$ 


\section{DISCUSSION}

Interest in medicinal use of cannabis and cannabinoids for chronic pain is increasing worldwide, and the number of patients who use it either by prescription or as self-medication is rising rapidly. $67,68 \mathrm{In}$ our clinical practice, we encounter patients seeking treatment with cannabis on a daily basis. Several factors may contribute to this observed rise in demand (Figure 1): first, an unmet need for pain relief. Chronic pain is an exceedingly prevalent medical problem, estimated to affect about one-fifth of the world's adult population. ${ }^{69}$ Treatment modalities for chronic pain include pharmaceutical, physical, psychological, and invasive measures, as well as complementary and alternative medicine. ${ }^{70}$ Even with best treatment, many patients continue to suffer from considerable symptoms, negatively affecting their quality of life. Effective pharmaceutical treatment options are rather limited, more so in light of appreciation of the adverse effects of longterm use of anti-inflammatory and opioid medications..$^{71,72}$ Second, public interest is fueled by favorable coverage of the medical virtues of cannabis by the mass media as well as in online resources, 73 contributing to the common perception of cannabis as a natural panacea, both safe and effective for a multitude of ailments. ${ }^{18}$ Finally, the increasing interest in medical cannabis is fueled by massive economic

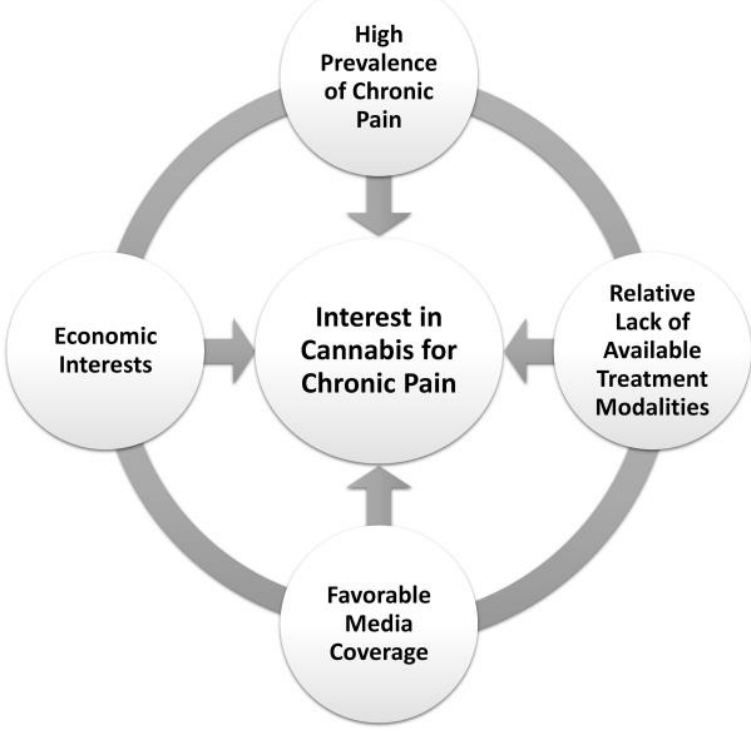

Figure 1. A Schematic Representation of Putative Factors Contributing to Rising Public Interest in Medicinal Cannabis for Chronic Pain. interests of a rapidly growing cannabis industry, 74 which is heavily invested in the medicalization of cannabis products.

This overwhelming demand for medical cannabis stands in contradiction to the paucity of evidence of its efficacy and safety. Thus, while some studies show a mild analgesic effect of cannabinoids in neuropathic pain and central pain, overall the available evidence on the safety and efficacy of cannabis for chronic pain is inconclusive. Recent meta-analyses suggest that many patients have to be treated in order for a few to benefit, while the risks of harm are significant.75 This could explain the reported discrepancy between the perception of the utility of cannabis among clinicians as compared to among patients. ${ }^{15,76}$ Nevertheless, despite the apparent lack of efficacy of cannabis for chronic pain as reflected in the medical literature, in our experience individual patients occasionally seem to draw considerable benefit from its use. Given the modest effect size on pain reduction, some have argued that the benefits could lie in other domains, such as positive effects on anxiety, sleep, and overall well-being. However, results of studies on the effects of cannabis in these domains do not support this notion. 77

The discrepancy between patients' opinion on the utility of cannabis for chronic pain and the lack of conclusive evidence of efficacy and safety is a common source of conflict in clinical practice. As clinical guidelines are lacking and evidence is scanty, the physician must make a decision under uncertainty. We propose a practical clinical approach to making a decision on cannabis treatment 55 :

1. Consider the indication: Is cannabis potentially effective for the patient's condition? Does the patient present with accompanying symptoms which may benefit from the use of cannabinoids (i.e. insomnia, cachexia)?

2. Consider other treatment modalities: Are there any other potentially effective treatment modalities, which have not yet been explored? Consider pharmaceutical, physical, psychological, and invasive options. This is not to say that cannabis should only be considered as a lastresort treatment, but, given the uncertainty of its efficacy and adverse effects profile, other, more established options may be considered first.

3. Consider contra-indications: In particular, patients should be assessed for: (a) psychiatric comorbidities-exclude patients deemed at risk 
for psychosis, mania, and suicidal tendency; (b) cardiovascular disease both established and with risk factors-while this is not an absolute contraindication, these patients warrant particular consideration before cannabis can be offered to them; (c) cognitive impairment-patients with limited cognitive reserve can suffer a significant impairment of function and independence if treated with cannabinoids; and (d) frailty, polypharmacy, and problems of gait and balance-these should be evaluated and addressed. To sum up, we suggest having an open discussion of the pros and cons of medical cannabinoids with the patient, raising possible cardiovascular, psychiatric, and cognitive effects, as well as potential effects on driving.

4. Assess benefit-risk profile: The benefit-risk function is individual and varies between patients and physicians, corresponding to their beliefs and values. It should also be noted that individuals receiving palliative care may sometimes be willing to take more risks in order to achieve improved quality of life, compared to individuals who are deemed to have longer life expectancies.

5. Begin treatment: We suggest defining the initial prescription of medical cannabis as a treatment trial.

6. Re-assessment: Following the initiation of a cannabinoid, a short-interval follow-up visit or telephone call is recommended. The treatment efficacy is evaluated for the various symptoms, and side effects are documented. We recommend very close and supportive guidance for patients receiving medical cannabis. ${ }^{60}$

The current state of uncertainty and lack of evidence calls for caution in the use of cannabis in clinical practice. The way for the full integration of cannabis as a pharmaceutical agent is still long: cannabis preparations will have to be standardized, such that the content of active molecules and their bioavailability is clear and consistent. In parallel, the entourage effect should be further studied. Furthermore, high-quality evidence from clinical trials and clinical registries is needed. ${ }^{78}$ Clinical registries should include options for clinicians and patients to report side effects and emergency room visits.

Until then, a cautious approach is recommended, weighing the evidence and individual patients' needs, without succumbing to public pressure.

\section{REFERENCES}

1. United States Drug Enforcement Administration. The Controlled Substances Act. Available at: https://www.dea.gov/controlled-substances-act (accessed January 16, 2020).

2. Dasgupta N, Beletsky L, Ciccarone D. Opioid crisis: no easy fix to its social and economic determinants. Am J Public Health 2018;108:182-6. CrossRef

3. NIDA. Opioid overdose crisis. 2019. Available at: https://www.drugabuse.gov/drugs-abuse/opioids/ opioid-overdose-crisis (accessed August 28, 2019).

4. Paulozzi LJ, Budnitz DS, Xi Y. Increasing deaths from opioid analgesics in the United States. Pharmacoepidemiol Drug Saf 2006;15:618-27. CrossRef

5. Florence CS, Zhou C, Luo F, Xu L. The economic burden of prescription opioid overdose, abuse and dependence in the United States, 2013. Med Care 2016;54:901-6. CrossRef

6. US Department of Health and Human Services, CDC. Overdose death rates involving opioids, by type, United States 2000-2017. Available at: https://www.cdc.gov/drugoverdose/images/data/Op ioidDeathsByTypeUS.PNG (accessed Aug 28, 2019).

7. The White House. Ending America's opioid crisis. Available at: https://www.whitehouse.gov/ opioids/ (accessed August 29, 2019).

8. Ong CKS, Lirk P, Tan CH, Seymour RA. An evidencebased update on nonsteroidal anti-inflammatory drugs. Clin Med Res 2007;5:19-34.

9. Wolfe MM, Lichtenstein DR, Singh G. Gastrointestinal toxicity of nonsteroidal antiinflammatory drugs. N Engl J Med 1999;340:1888-99. CrossRef

10. Hayes MJ, Brown MS. Legalization of medical marijuana and incidence of opioid mortality. JAMA Intern Med 2014;174:1673-4. $\underline{\text { CrossRef }}$

11. Svrakic DM, Lustman PJ, Mallya A, Lynn TA, Finney R, Svrakic NM. Legalization, decriminalization \& medicinal use of cannabis: a scientific and public health perspective. Mo Med 2012;109:90-8.

12. Bostwick JM. Blurred boundaries: the therapeutics and politics of medical marijuana. Mayo Clin Proc 2012;87:172-86. CrossRef

13. Zarhin D, Negev M, Vulfsons S, Sznitman SR. Rhetorical and regulatory boundary-work: the case of medical cannabis policy-making in Israel. Soc Sci Med 2018;217:1-9. CrossRef

14. Zarhin D, Negev M, Vulfsons S, Szintman S. Medicalization of cannabis: what does it mean? Int J Drug Policy 2017;49:54-7. CrossRef

15. Zolotov Y, Vulfsons S, Zarhin D, Sznitman S. Medical cannabis: an oxymoron? Physicians' perceptions of 
medical cannabis. Int J Drug Policy 2018;57:4-10. CrossRef

16. Ebert T, Zolotov Y, Eliav S, Ginzburg O, Shapira I, Magnezi R. Assessment of Israeli physicians' knowledge, experience and attitudes towards medical cannabis: a pilot study. Isr Med Assoc J 2015;17:437-41.

17. Zolotov Y, Vulfsons S, Sznitman S. Predicting physicians' intentions to recommend medical cannabis. J Pain Symptom Manage 2019;58:400-7. CrossRef

18. Sznitman SR, Lewis N. Is cannabis an illicit drug or a medicine? A quantitative framing analysis of Israeli newspaper coverage. Int J Drug Policy 2015;26:44652. CrossRef

19. Niv D, Devor M. Chronic pain as a disease in its own right. Pain Pract 2004;4:179-81. $\underline{\text { CrossRef }}$

20. Buggy DJ, Toogood L, Maric S, Sharpe P, Lambert DG, Rowbotham DJ. Lack of analgesic efficacy of oral $\Delta$-9-tetrahydrocannabinol in postoperative pain. Pain 2003;106:169-72. CrossRef

21. Holdcroft A, Maze M, Doré C, Tebbs S, Thompson S. A multicenter dose-escalation study of the analgesic and adverse effects of an oral cannabis extract (Cannador) for postoperative pain management. Anesthesiology 2006;104:1040-6. $\underline{\text { CrossRef }}$

22. Kraft B, Frickey NA, Kaufmann RM, et al. Lack of analgesia by oral standardized cannabis extract on acute inflammatory pain and hyperalgesia in volunteers. Anesthesiology 2008;109:101-10. CrossRef

23. Beaulieu P. Effects of nabilone, a synthetic cannabinoid, on postoperative pain. Can J Anesth 2006;53: 769-75. CrossRef

24. Iskedjian M, Bereza B, Gordon A, Piwko C, Einarson TR. Meta-analysis of cannabis based treatments for neuropathic and multiple sclerosis-related pain. Curr Med Res Opin 2007;23:17-24. $\underline{\text { CrossRef }}$

25. Cepeda MS, Africano JM, Polo R, Alcala R, Carr DB. What decline in pain intensity is meaningful to patients with acute pain? Pain 2003;105:151-7. $\underline{\text { CrossRef }}$

26. Kendrick DB, Strout TD. The minimum clinically significant difference in patient-assigned numeric scores for pain. Am J Emerg Med 2005;23:828-32. CrossRef

27. Lynch ME, Campbell F. Cannabinoids for treatment of chronic non-cancer pain; a systematic review of randomized trials. Br J Clin Pharmacol 2011;72:73544. $\underline{\text { CrossRef }}$

28. Frank B, Serpell MG, Hughes J, Matthews JNS, Kapur D. Comparison of analgesic effects and patient tolerability of nabilone and dihydrocodeine for chronic neuropathic pain: randomised, crossover, double blind study. BMJ 2008;336:199-201. CrossRef
29. Svendsen KB, Jensen TS, Bach FW. Does the cannabinoid dronabinol reduce central pain in multiple sclerosis? Randomised double blind placebo controlled crossover trial. BMJ 2004;329:253. CrossRef

30. Lynch ME, Ware MA. Cannabinoids for the treatment of chronic non-cancer pain: an updated systematic review of randomized controlled trials. J Neuroimmune Pharmacol 2015;10:293-301. $\underline{\text { CrossRef }}$

31. Plotnikoff R, Karunamuni N, Lytvyak E, et al. Osteoarthritis prevalence and modifiable factors: a population study. BMC Public Health 2015;15:1195. CrossRef

32. Manchikanti L, Singh V, Falco FJ, Benyamin RM, Hirsch JA. Epidemiology of low back pain in adults. Neuromodulation 2014;17(Suppl 2):3-10. CrossRef

33. Crombie IK, Davies HTO, Macrae WA. Cut and thrust: antecedent surgery and trauma among patients attending a chronic pain clinic. Pain 1998;76:167-71. CrossRef

34. Madden K, van der Hoek N, Chona S, et al. Cannabinoids in the management of musculoskeletal pain: a critical review of the evidence. JBJS Rev 2018;6:e7. CrossRef

35. Walitt B, Klose P, Fitzcharles M, Phillips T, Häuser W. Cannabinoids for fibromyalgia. Cochrane Database Syst Rev 2016 Jul 18;7:CD011694. CrossRef

36. Skrabek RQ, Galimova L, Ethans K, Perry D. Nabilone for the treatment of pain in fibromyalgia. J Pain 2008;9:164-173. $\underline{\text { CrossRef }}$

37. Ware MA, Fitzcharles M-A, Joseph L, Shir Y. The effects of nabilone on sleep in fibromyalgia: results of a randomized controlled trial. Anesth Analg 2010; 110:604-10. $\underline{\text { CrossRef }}$

38. van de Donk T, Niesters M, Kowal MA, Olofsen E, Dahan A, van Velzen M. An experimental randomized study on the analgesic effects of pharmaceuticalgrade cannabis in chronic pain patients with fibromyalgia. Pain 2019;160:860-9. CrossRef

39. Katz N. The impact of pain management on quality of life. J Pain Symptom Manage 2002;24(1 Suppl):S3847. CrossRef

40. Haroutounian S, Ratz Y, Ginosar Y, et al. The effect of medicinal cannabis on pain and quality-of-life outcomes in chronic pain: a prospective open-label study. Clin J Pain 2016;32:1036-43. CrossRef

41. Fiz J, Durán M, Capellà D, Carbonell J, Farré M. Cannabis use in patients with fibromyalgia: effect on symptoms relief and health-related quality of life. PLoS One 2011;6:e18440. $\underline{\text { CrossRef }}$

42. Allan GM, Finley CR, Ton J, et al. Systematic review of systematic reviews for medical cannabinoids: pain, nausea and vomiting, spasticity, and harms. Can Fam Physician 2018;64:e78-94. 
43. Wang T, Collet J-P, Shapiro S, Ware MA. Adverse effects of medical cannabinoids: a systematic review. CMAJ 2008;178:1669-78. CrossRef

44. Whiting PF, Wolff RF, Deshpande S, et al. Cannabinoids for medical use: a systematic review and metaanalysis. JAMA 2015;313:2456-73. CrossRef

45. Aviram J, Samuelly-Leichtag G. Efficacy of cannabisbased medicines for pain management: a systematic review and meta-analysis of randomized controlled trials. Pain Physician 2017;20:E755-96.

46. Deshpande A, Mailis-Gagnon A, Zoheiry N, Lakha SF. Efficacy and adverse effects of medical marijuana for chronic noncancer pain. Can Fam Physician 2015;61: e372-81.

47. Grant I, Atkinson JH, Gouaux B, Wilsey B. Medical marijuana: clearing away the smoke. Open Neurol J 2012;6:18-25.

48. Volkow ND, Baler RD, Compton WM, Weiss SRB. Adverse health effects of marijuana use. N Engl J Med 2014;370:2219-27. $\underline{\text { CrossRef }}$

49. Broyd SJ, van Hell HH, Beale C, Yücel M, Solowij N. Acute and chronic effects of cannabinoids on human cognition-a systematic review. Biol Psychiatry 2016; 79:557-67. $\underline{\text { CrossRef }}$

50. Epstein KA, Kumra S. Altered cortical maturation in adolescent cannabis users with and without schizophrenia. Schizophr Res 2015;162:143-52. CrossRef

51. Smith MJ, Cobia DJ, Wang L, et al. Cannabis-related working memory deficits and associated subcortical morphological differences in healthy individuals and schizophrenia subjects. Schizophr Bull 2014;40:28799. CrossRef

52. Moore $\mathrm{TH}$, Zammit $\mathrm{S}$, Lingford-Hughes $\mathrm{A}$, et al. Cannabis use and risk of psychotic or affective mental health outcomes: a systematic review. Lancet 2007; 370:319-28. $\underline{\text { CrossRef }}$

53. Sagy I, Bar-Lev Schleider L, Abu-Shakra M, Novack V. Safety and efficacy of medical cannabis in fibromyalgia. J Clin Med 2019;8:807. $\underline{\text { CrossRef }}$

54. Fischer B, Russell C, Sabioni P, et al. Lower-risk cannabis use guidelines: a comprehensive update of evidence and recommendations. Am J Public Health 2017;107:e1-12. $\underline{\text { CrossRef }}$

55. Minerbi A, Häuser W, Fitzcharles MA. Medical cannabis for older patients. Drugs Aging 2019;36:3951. $\underline{\text { CrossRef }}$

56. Brown JD, Winterstein AG. Potential adverse drug events and drug-drug interactions with medical and consumer cannabidiol (CBD) use. J Clin Med 2019; 8:E989. CrossRef

57. Itin C, Mechtiger-Azoulay N, Ratz Y, Yosselson Superstine S, Schumacher I. Main adverse events and drug-drug interactions of medical cannabis. Circular of the Deputy Director General's Office, Israeli Ministry of Health. Medical Cannabis Unit (YCAR), Deputy Director General's Office, Ministry of Health. Jerusalem, Israel; 2019. Available at: https://www.health.gov.il/hozer/mmk154 2016.pdf (accessed January 18, 2020) [Hebrew].

58. Kalant H, Porath-Waller AJ. Clearing the smoke on cannabis: medical use of cannabis and cannabinoids - an update. Canadian Centre on Substance Use and Addiction. Available at: https://www.ccsa.ca/ clearing-smoke-cannabis-medical-use-cannabis-andcannabinoids-update (accessed November 2, 2019).

59. MacCallum CA, Russo EB. Practical considerations in medical cannabis administration and dosing. Eur $\mathrm{J}$ Intern Med 2018;49:12-19. $\underline{\text { CrossRef }}$

6o. Benny Leeat. A unique protocol - medical cannabis treatment for oncological patients. Israeli J Oncol Nurs 2017;29:13-8. Available at: https://www.ions.org.il/ImagesFck/Siud/file/\%D7\% 91\%D7\%98\%D7\%90\%D7\%95\%D7\%9F\%20\%D7\%A1 \%D7\%99\%D7\%A2\%D7\%95\%D7\%93\%20\%D7\%90\%D 7\%95\%D7\%A0\%D7\%A7\%D7\%95\%D7\%9C\%D7\%95\% D7\%92\%D7\%99/2017/13-19.pdf (accessed January 18, 2020) [Hebrew].

61. Ablin J, Ste-Marie PA, Schäfer M, Häuser W, Fitzcharles M-A. Medical use of cannabis products: lessons to be learned from Israel and Canada. Schmerz 2016;30:3-13. CrossRef

62. Rong C, Carmona NE, Lee YL, et al. Drug-drug interactions as a result of co-administering $\Delta 9$-THC and CBD with other psychotropic agents. Expert Opin Drug Saf 2018;17:51-4. CrossRef

63. US food and Drug Administration (FDA). What you should know about using cannabis, including CBD, when pregnant or breastfeeding. Available at: http://www.fda.gov/consumers/consumerupdates/what-you-should-know-about-usingcannabis-including-cbd-when-pregnant-orbreastfeeding (accessed November 7, 2019)

64. US Department of Health and Human Services. Office of the Surgeon General. Surgeon General's Advisory: Marijuana Use \& the Developing Brain [Internet]. August 29, 2019. Available at: https://www.hhs.gov/surgeongeneral/reports-andpublications/addiction-and-substance-misuse/ advisory-on-marijuana-use-and-developingbrain/index.html (accessed November 14, 2019).

65. National Academies of Sciences, Engineering, and Medicine; Health and Medicine Division; Board on Population Health and Public Health Practice; Committee on the Health Effects of Marijuana: An Evidence Review and Research Agenda. The Health Effects of Cannabis and Cannabinoids: The Current 
State of Evidence and Recommendations for Research. Washington, DC: National Academies Press (US); 2017. Available at: http://www.ncbi.nlm.nih. gov/books/NBK423845/ (accessed November 14, 2019).

66. Brents LK. Marijuana, the endocannabinoid system and the female reproductive system. Yale J Biol Med 2016;89:175-91.

67. Han B, Compton WM, Blanco C, Jones CM. Trends in and correlates of medical marijuana use among adults in the United States. Drug Alcohol Depend 2018;186:120-9. CrossRef

68. Compton WM, Han B, Hughes A, Jones CM, Blanco C. Use of marijuana for medical purposes among adults in the United States. JAMA 2017;317:209-11. CrossRef

69. Breivik H, Collett B, Ventafridda V, Cohen R, Gallacher D. Survey of chronic pain in Europe: prevalence, impact on daily life, and treatment. Eur J Pain 2006;10:287-333. $\underline{\text { CrossRef }}$

70. Finnerup NB. Nonnarcotic methods of pain management. N Engl J Med 2019;380:2440-8. CrossRef

71. Okie S. A flood of opioids, a rising tide of deaths. $\mathrm{N}$ Engl J Med 2010;363:1981-5. CrossRef

72. Trelle S, Reichenbach S, Wandel S, et al. Cardiovascular safety of non-steroidal anti-inflammatory drugs: network meta-analysis. BMJ 2011;342:c7086. CrossRef

73. Lewis N, Sznitman SR. Engagement with medical cannabis information from online and mass media sources: is it related to medical cannabis attitudes and support for legalization? Int J Drug Policy 2019;73:219-27. CrossRef

74. McNish J, Monga V. Wall Street's marijuana madness: 'it's like the internet in 1997'. The Wall Street Journal January 17, 2020. Available at: https://www.wsj.com/articles/wall-streetsmarijuana-madness-its-like-the-internet-in-19971537718400 (accessed October 30, 2019).

75. Hill KP. Medical use of cannabis in 2019. JAMA 2019;322:974-5. $\underline{\text { CrossRef }}$

76. Sznitman SR, Bretteville-Jensen AL. Public opinion and medical cannabis policies: examining the role of underlying beliefs and national medical cannabis policies. Harm Reduct J 2015;12:46. $\underline{\text { CrossRef }}$

77. Black N, Stockings E, Campbell G, et al. Cannabinoids for the treatment of mental disorders and symptoms of mental disorders: a systematic review and meta-analysis. Lancet Psychiatry 2019;6:9951010. CrossRef

78. Fitzcharles M-A, Shir Y, Häuser W. Medical cannabis: strengthening evidence in the face of hype and public pressure. CMAJ 2019;191:E907-8. CrossRef 